there has been no advance in our knowledge of an effective cure for guinea-worm which will cut short the tedium and risk of slow extraction by winding in vogue for so many years. It is, therefore, greatly to be hoped that future trials of this apparently successful mode of treatment may result in its recognition as a certain and reliable remedy. I am, Sir, yours faithfully, Savoy Hill, W.C., April 6th, 1920. J. GRAHAM FORBES.

\section{THE PATHOLOGY OF HEAT.STROKE.}

\section{To the Editor of THE LANCET.}

SIR,-The intimation in THE LANCET of March 20th by Dr. W. H. Willcox that he regards heat-stroke as an auto-intoxication, and the report of the observation of a leucocytosis in the cerebro-spinal fluid in the same condition by two French workers, both call attention to the fact that there seems to be rather a dearth of information as to the pathology of the condition.

The following notes, unfortunately from memory, may be of interest. Three cases occurring in men of the Guards' Division who had done a long march with ful kits under a hot sun came under my care in 1917. One proved fatal in a few hours. At the post-mortem changes indicative of a far-reaching morbid process came to light. In addition to congestion of the cerebral vessels there were petechial hxmorrhages of the pia over the cerebral hemispheres, also of the pericardium, endocardium, and pleura; in one lung, though I cannot exactly remember where, there was a large and very definite area of congestion; there was also a slight increase of the pleural fluid.

In view of my previous entirely unfounded prepossession that the condition was solely a matter of the central nervous system these evidences of widespread damage were surprising. They certainly seem to confirm the suggestion that a toxic agency is at work. In both the cases which survived I found that the headache was relieved by lumbar puncture, which disclosed the fact that the cerebro-spinal fluid was in excess and under pressure. It was perfectly clear, but unfortunately, owing to a rush of work, no investigation of its cytology was undertaken.

I am, Sir, yours faithfully,

S. C. DYKE, M.B., B.Ch., D.P.H. Oxon., Assistant Bacteriologist, College of Medicine,

Gosforth, March 20th, 1920. Newcastle-upon-Tyne.

\section{VACCINES AND THE DIPHTHERIA CARRIER. To the Editor of THE LANCET.}

SIR,-The results obtained by Dr. J. L. Brownlie (THE LANCET, March 27th) in the treatment of the convalescent diphtheria "carrier," whilst of the greatest possible importance to the community in general, possess particular interest to workers at Guy's. Since the very early days of the present century it has been our practice to treat with vaccines all'students and nurses who develop the carrier habit, and it was the results we obtained that prompted the following paragraph in "Serums, Vaccines, and Toxins" in 1910 (p.107, repeated in the 1916 edition, pp. 135-176): "In such cases (i.e., cases in which the diphtheria bacillus remains domiciled in the throat, \&c., for prolonged periods after the acute clinical symptoms have disappeared) a vaccine should be prepared from that strain of $B$. diphtherice actually infecting the patient, standardised and administered in doses of 5 to 10 millions at intervals of five to seven days. One or two injections are usually sufficient to ensure the disappearance of the bacilli from the local site of infection."

The opportunities afforded by a general hospital for the collection of statistical observations in this connexion are limited (for here we certainly do not total more than a score of diphtheria cases per annum), and we consequently welcome the confirmatory evidence on a figure basis so convincingly set out by Dr. Brownlie. My object, however, in writing this note is to point out the two important features in which our practice differs from that of Dr. Brownlie. In the first place, we are convinced of the superiority of the "autogenous" as against the "stock" vaccine, and in the second we insist upon washing the bacilli with several changes of normal saline before using them in the preparation of our vaccine. It is true that, when grown upon solid media, the diphtheria bacillus only forms a modicum of toxin, but strains vary in this respect, and neglect of precautionary measures may lead on occasion to the production of uncomfortable local reactions.

I am, Sir, yours faithfully,

Guy's Hospital, S.E., March 31st, 1920. JNO. EYRE.

\section{LAVAGE OF THE CLOSED PLEURAL CAVITY}

\section{To the Editor of THE LANCET.}

SIR,-With great pleasure and approval I have read Dr. F. G. Chandler's paper on Oxygen and Air Replacement of Fluid in the Pleural Cavity in THE LANCET of April 3rd, but I would like to point out that lavage of the closed pleural cavity is not new, as Dr. Chandler believes. In a paper on Penetrating Wounds of the Chest, which I published, in collaboration with Major G. C. Shattuck, of Boston, U.S.A., in the Journal of the Royal Army Medical Corps of September, 1919, I made reference to lavage of closed chests. I quote my own words: "Irrigation of the pleural cavity can be performed through the aspirating needle on the syphon principle. Aspiration, sometimes assisted by what may be called 'aspiration-irrigation,' may be the means of effecting a cure when the infec. tion is not too severe."

I am, Sir, yours faithfully.

R. Bertram BLAIR, M.B., F.R.C.S.Edin., Honorary Assistant Surgeon, Hull Royal Infirmary. Albion-street, Hull, April 1st, 1920.

\section{TUBERCULOSIS AND PENSIONS.}

\section{To the Editor of THE LANCET.}

SIR,-Dr. John Guy's note on the Diagnosis of Tuberculosis in Recruits and Pensioners in your issue of March 27th deals with a subject of great importance and one which has been repeatedly discussed by the North of England Tuberculosis Society. My own experience is similar to Dr. Guy's, and my figures, compiled up to Dec. 31st last, show that of 313 ex-Service men who applied for sanatorium benefit 180 had had tuberele bacilli demonstrated in their sputum, and of the remainder 43 had signs of presumptive tuberculosis, while 90 , or 28.7 per cent. of the total applicants, showed no evidence of any active tuberculous disease. Surely we have already a sufficient number of tuberculous patients without dissipating our funds on individuals for whom the sanatorium benefit provisions of the Insurance Act were not intended. If, and when, the proposed farm and industrial colonies and village settlements are instituted it is to be hoped that all applicants will be required to undergo a rigorous and searching examination to ensure that the facilities provided will be offered only to persons who are suffering from, or have recently suffered from, clinically recognisable tuberculosis. I am, Sir, yours faithfully, W. H. DICKINSON,

Tuberculosis Medical Officer, Newcastle-upon-Tyne. March 30th, 1920

A WAR Memortat TO BELgIAN Doctors.-From Le Scalpel for March 27th we learn that the project for a war memorial to Belgian doctors and pharmacists who died or were killed on active service is being energetically conducted by Dr. Clement Philippe. It is proposed to erect a monument in granite in the Place des Barricades at Brussels, near to the statue of Vésale. M. Cancel has been entrusted with its design and execution.

INFLUENZA IN ZURICH.-The epidemic of influenza in Zurich (population 210,000) has now come to an end. 14,534 cases have been reported since Jan. 4th. The total number for January was 1071; in February the records of the four weeks showed 2721,4140,3341, and 1899 cases respectively; in March the decrease was rapid, 866, 442, and 45 cases being notified in the first three weeks. The total number of deaths, mostly due to pneumonia, was 229, a mortality of $1 \frac{1}{2}$ per cent. In the Canton of Zarich (population 579,000$) 141$ cases of encephalitis lethargica have occurred, with a mortality of about 30 per cent. 